\title{
Tingkat Pengetahuan PUS Tidak Berhubungan dengan Keikutsertaan KB di Desa Argomulyo, Sedayu, Bantul Yogyakarta
}

\author{
Ardhiyani Muslimah ${ }^{1}$, Nur Indah Rahmawati² \\ 1,2 Sekolah Tinggi IImu Kesehatan Alma Ata Yogyakarta \\ Jalan Ringroad Barat Daya No 1 Tamantirto, Kasihan, Bantul, Yogyakarta
}

\begin{abstract}
Abstrak
Keikutsertaan KB merupakan hal terpenting dalam keberhasilan program Keluarga Berencana di Indonesia. Berdasarkan studi pendahuluan keikutsertaan KB di 6 dusun di desa Argomulyo sebanyak 533 PUS (59,22\%) dari 900 PUS. Tingkat pengetahuan merupakan salah satu faktor yang menyebabkan PUS mengikuti atau tidak mengikuti program KB. Pengetahuan adalah hal yang dijadikan dasar dari suatu aksi untuk memecahkan masalah dan ini merupakan hasil dari tahu setelah orang melakukan pengindraan terhadap objek tertentu. Pengetahuan tentang Keluarga Berencana diharapkan dapat menimbulkan keikutsertaan PUS dalam program KB. Tujuan penelitian ini untuk mengetahui hubungan antara tingkat pengetahuan tentang KB dengan keikutsertaan KB pada PUS di desa Argomulyo, Sedayu, Bantul Yogyakarta tahun 2014. Metode penelitian observasional analitik dengan pendekatan cross sectional. Teknik sampling dengan total sampling PUS di desa Argomulyo, Sedayu, Bantul, Yogyakarta berjumlah 907 responden. Pengambilan data dilakukan dengan wawancara menggunakan panduan kuesioner. Uji analisa yang digunakan dengan chi-square. Hasil penelitian diperoleh p-value 0,318>(0,05) dan koefisien kontingensi sebesar 0,05 sehingga tingkat pengetahuan tentang KB tidak mempunyai hubungan dengan keikutsertaan KB pada PUS. Tingkat pengetahuan mayoritas baik $71,00 \%$, sedangkan keikutsertaan KB tertinggi yaitu pada PUS yang berpengetahuan cukup 68,8\%, sedangkan tidak ikut serta tertinggi pada PUS dengan pengetahuan kurang 41,8\%. Kesimpulan tidak ada hubungan signifikan antara Tingkat Pengetahuan tentang KB dengan Keikutsertaan KB pada PUS di Desa Argomulyo, Sedayu, Bantul, Yogyakarta tahun 2014.
\end{abstract}

Kata Kunci: keikutsertaan KB, PUS, tingkat pengetahuan KB

\section{The Knowledge Level of Reproductive Age Couples Had No Relationship with Family Planning Participation in Argomulyo Village, Sedayu, Bantul, Yogyakarta}

\begin{abstract}
Family Planning (FP) participation is the most important thing in the family planning program in Indonesia. Based on the baseline study, family planning participations in 6 in Argomulyo village covered 533 couples (59.22\%) of 900 total couple of reproductive age. Knowledge is one of the factors that causes reproductive age couples to join the family planning program. Knowledge is used as the basis of actions to solve problems and this was the result of knowing after the people recognice an object. Knowledge about family planning is expected to cause the participation of reproductive age couples in the family planning program. The purpose of this study was to analyze the relationship between the knowledge level of family planning participation in reproductive age couples in Argomulyo village, Sedayu, Bantul, Yogyakarta 2014. Study design was observational analytic with cross sectional aproach. Technique sampling used was total sampling of reproductive age couples in Argomulyo village, Sedayu, Bantul, Yogyakarta resulted on 907 respondents. Data was colected by interview using the questionnaire. The analysis used was chi-square. The result of chi-square test showed a p-value $0.318>(0.05)$ and coefficients contingency of 0.05 so knowledge level had no relationship with FP participation. Knowledge level was $71.00 \%$ good, while the highest participation of family planning in the majority of with fair level enough was $68.8 \%$, in addition, the highest proportion of couples who did not participate in FP program was $41.8 \%$. In Conclusion, there was no significant relationship between the knowledge level about family planning and the participation of the family planning in reproductive age couples in Argomulyo village, Sedayu, Bantul, Yogyakarta year 2014.
\end{abstract}

Keywords: reproductive age couples, FP participation, the family planning knowledge

Info Artikel:

Artikel dikirim pada 19 Agustus 2014

Artikel diterima pada 21 Agustus 2014 


\section{PENDAHULUAN}

Perkembangan penduduk dunia saat ini terus mengalami peningkatan, pada tahun 2012 urutan pertama di tempati oleh China dengan jumlah penduduk $1.354,8$ juta jiwa, peringkat ke dua di duduki oleh India dengan jumlah penduduk 1.261,0 juta jiwa, peringkat ke tiga diduduki oleh Amerika Serikat dengan jumlah penduduk 315,8 juta jiwa dan penduduk Indonesia menempati urutan ke empat dunia yaitu sebesar 244,2 juta jiwa(1). Indonesia merupakan salah satu negara berkembang dengan berbagai jenis masalah. Masalah utama yaitu ledakan jumlah penduduk yang beberapa tahun terakhir ini sulit terkontrol. Upaya merenda keluarga bahagia, perlu berbagai peran dengan andil suami istri, berusaha mengatasi krisis keluarga dan mengkukuhkan integritas keluarga(2).

Pemerintah terus berupaya untuk menekan laju pertumbuhan dengan Program Keluarga Berencana(3). Sasaran program KB dibagi menjadi 2 yaitu sasaran langsung dan tidak langsung tergantung dari tujuan yang akan dicapai. Sasaran langsung adalah pasangan usia subur (PUS) yang bertujuan untuk menurunkan tingkat kelahiran dengan cara penggunaan kontrasepsi secara berkelanjutan. Sasaran tidak langsung adalah pelaksana dan pengolah KB, dengan tujuan menurunkan tingkat kelahiran melalui pendekatan kebijaksanaan kependudukan terpadu dalamrangka mencapai keluarga yang berkualitas, dan keluarga sejahtera. Berdasarkan hasil survey BKKPPKB tahun 2013 Jumlah Pasangan Usia Subur di Provinsi DIY adalah 554.531 dengan peserta KB aktif 444.718 $(80,19 \%)$ dan KB baru 55.069 (9,93\%). Jumlah pasangan usia subur di Kabupaten Bantul adalah 152.793. Peserta KB aktif berdasarkan alat kontrasepsi di Kabupaten Bantul terdapat sejumlah 124.372 $(81,39 \%)$, sementara pasangan usia subur yang bukan peserta KB ada sebanyak 28.421 sementara pasangan usia subur yang bukan peserta KB ada sebanyak 28.421, dan peserta KB Baru 15.081 $(9,87 \%)$. Kecamatan Sedayu memiliki Pasangan Usia Subur yang sudah aktif menggunakan alat kontrasepsi sebanyak 6.195 peserta dari 7.727 PUS yang ada $(79,78 \%)$. Persentase tersebut lebih rendah dibandingkan dengan Contraceptive Prevalence Rate (CPR) atau angka pemakaian kontrasepsi rata-rata Kabupaten Bantul yang telah mencapai 81,40\%(1). Jumlah pasangan usia subur di Kecamatan Sedayu sebagai peserta KB aktif berdasarkan alat kontrasepsi sejumlah $6.477(83,46 \%)$ dan peserta KB baru 743 $(9,57 \%)(4)$. Berdasarkan hasil data yang didapat dari Badan Pusat Statistik 2013, Daerah Istimewa Yogyakarta, jumlah pasangan usia subur di Desa Argomulyo yang terdiri dari 14 dusun pada tahun 2012 sebanyak 2.188 pasangan. Pasangan yang menjadi peserta KB aktif pada tahun 2012 sebanyak 1.822 peserta, sementara pasangan usia subur yang bukan peserta KB ada sebanyak 361.

Berdasarkan hasil studi pendahuluan pada 6 Dusun (Puluhan, Kemusuk, Karang Lo, Pedes, Kali Berot dan Surobayan) diketahui bahwa jumlah PUS tahun 2013 adalah 900 pasangan dan jumlah PUS yang mengikuti KB sejumlah 533 pasangan atau sekitar $59,22 \%$. Jika dilihat dari persentase berdasarkan data di atas, akseptor KB di 6 Dusun di Desa Argomulyo masih rendah. Keikutsertaan KB pada PUS di pengaruhi oleh beberapa faktor yaitu pengetahuan, pendidikan, agama, jumlah anak yang diinginkan, sosial ekonomi dan dukungan pasangan atau dukungan keluarga akan mempengaruhi perkembangan dan kemajuan program KB di Indonesia. Dengan jumlah peserta KB aktif 533 atau sekitar $59,22 \%$ peneliti tertarik menggali sisi tingkat pengetahuan PUS dimana pengetahuan yang benar tentang program KB termasuk jenis kontrasepsi akan mempertinggi keikutsertaan masyarakat dalam program $\mathrm{KB}(5)$. Tujuan penelitian untuk mengetahui hubungan antara tingkat pengetahuan tentang KB dengan keikutsertaan KB pada PUS di desa Argomulyo.

\section{BAHAN DAN METODE}

Penelitian ini menggunakan metode penelitian observasional yang didukung oleh deskriptif analitik. Desain penelitian menggunakan rancangan cross sectional. Populasi adalah keseluruhan subyek penelitian. Subyek penelitian berupa benda, semua benda yang memiliki sifat atau ciri, adalah subyek yang bisa diteliti(6). Populasi dalam penelitian ini adalah semua pasangan usia subur (PUS) di Dusun Puluhan, Karang Lo, Kemusuk Kidul, Pedes, Surobayan, Kaliberot, Desa Argomulyo, Sedayu, Bantul, Yogyakarta yaitu sebanyak 916 pasangan usia subur (PUS). Teknik pengambilan sampel menggunakan total sampling. Penelitian ini dilakukan di 6 dusun, desa Argomulyo, Sedayu, Bantul, Yogyakarta yaitu: Puluhan, Kemusuk Kidul, Karang Lo, Pedes, Surobayan, dan Kaliberot, mulai tanggal 3-18 Juni 2014. Instumen penelitian menggunakan kuesioner. Jenis kuesioner yang digunakan berbentuk pilihan, dimana jawaban telah disediakan (closed ended item). Variabel bebas dalam penelitian ini adalah tingkat pengetahuan tentang KB. Variabel terikat dalam penelitian ini adalah keikutsertaan KB pada PUS.

\section{HASIL DAN BAHASAN}

\section{Analisis Univariat}

Jumlah responden yang menjadi subjek penelitian dalam penelitian ini adalah 907 responden. 
Responden kemudian dikelompokkan berdasarkan karakteristik Umur PUS, Agama PUS, Pendidikan PUS, dan Pekerjaan PUS. Distribusi karakteristik responden dapat dilihat pada Tabel 1.

Tabel 1. Distribusi Frekuensi Karakteristik Responden Pasangan Usia Subur (PUS) Berdasarkan Umur, Agama, Pendidikan, Pekerjaan di Desa Argomulyo, Sedayu, Bantul, Yogyakarta tahun 2014

\begin{tabular}{|c|c|c|c|c|}
\hline \multirow{2}{*}{ Karakteristik } & \multicolumn{2}{|c|}{ Istri } & \multicolumn{2}{|c|}{ Suami } \\
\hline & f & $\%$ & f & $\%$ \\
\hline \multicolumn{5}{|l|}{ Umur } \\
\hline$<20$ Tahun & 4 & 0,4 & 1 & 0,1 \\
\hline 20-35 Tahun & 476 & 52,5 & 383 & 42,2 \\
\hline$>35$ Tahun & 427 & 47,1 & 523 & 57,7 \\
\hline \multicolumn{5}{|l|}{ Agama } \\
\hline Islam & 888 & 97,9 & 888 & 97,9 \\
\hline Kristen & 10 & 1,1 & 10 & 1,1 \\
\hline Budha & 0 & 0 & 0 & 0 \\
\hline Hindu & 0 & 0 & 0 & 0 \\
\hline Katholik & 9 & 1,0 & 9 & 1,0 \\
\hline Khonghucu & 0 & 0 & 0 & 0 \\
\hline \multicolumn{5}{|l|}{ Pendidikan } \\
\hline Tidak Tamat SD & 9 & 1,0 & 10 & 1,1 \\
\hline Tamat SD/Sederajat & 82 & 9,0 & 78 & 8,6 \\
\hline Tamat SMP/Sederajat & 150 & 16,5 & 127 & 14,0 \\
\hline Tamat SMA/Sederajat & 548 & 60,4 & 563 & 62,1 \\
\hline Tamat Diploma/Lebih Tinggi & 118 & 13,0 & 129 & 14,2 \\
\hline \multicolumn{5}{|l|}{ Pekerjaan } \\
\hline Petani/Peternak/Nelayan & 12 & 1,3 & 20 & 2,2 \\
\hline Buruh/Buruh Tani & 148 & 16,3 & 304 & 33,5 \\
\hline Karyawan Swasta & 165 & 18,2 & 327 & 36,1 \\
\hline PNS/TNI/POLRI & 25 & 2,8 & 46 & 5,1 \\
\hline Wiraswasta & 136 & 15,0 & 187 & 20,6 \\
\hline Tidak Bekerja/IRT & 404 & 44,5 & 3 & 0,3 \\
\hline Lain-Lain & 17 & 1,9 & 20 & 2,2 \\
\hline Jumlah & 907 & 100 & 907 & 100 \\
\hline
\end{tabular}

Sumber: Data Primer Tahun 2014

Berdasarkan Tabel 1 karakteristik responden meliputi: Kriteria umur istri yang termasuk dalam penelitian ini yaitu umur 15-49 tahun. Dari tabel karakteristik umur istri mayoritas memiliki umur antara 20-35 tahun sebanyak 476 responden $(52,5 \%)$, sedangkan umur suami mayoritas berada pada umur $>35$ tahun yaitu 523 responden $(57,7 \%)$. Mayoritas agama PUS yaitu Islam sebanyak 888 responden $(97,9 \%)$, Kristen 10 responden $(1,1 \%)$, dan Khatolik sebanyak 9 responden $(1,0 \%)$. Karakteristik pendidikan responden yaitu pendidikan PUS mayoritas adalah tamat SMA/sederajat. Pendidikan istri terendah yaitu tidak tamat SD 9 responden $(1,0 \%)$, sedangkan mayoritas tamat SMA/sederajat 548 responden $(60,4 \%)$. Pendidikan suami terendah tidak tamat SD 10 responden $(1,1 \%)$, mayoritas pendidikan suami tamat SMA/sederajat 563 responden $(62,1 \%)$. Mayoritas pekerjaan istri yaitu tidak bekerja/IRT sebanyak 404 responden (44,5\%). Mayoritas pekerjaan suami yaitu karyawan swasta 327 responden $(36,1 \%)$ terendah adalah tidak bekerja 3 responden $(0,3 \%)$.

\section{Tingkat Pengetahuan PUS tentang KB}

Tingkat pengetahuan responden dalam penelitian ini dibagi menjadi 3 kriteria yaitu baik $(>75 \%)$, cukup $(56-75 \%)$, kurang $(<55 \%)(6)$. Tingkat pengetahuan responden dalam penelitian ini dapat dilihat dari Tabel 2.

Tabel 2. Distribusi Frekuensi Responden Pasangan Usia Subur (PUS) Berdasarkan Tingkat Pengetahuan tentang KB di Desa Argomulyo, Sedayu, Bantul, Yogyakarta Tahun 2014

\begin{tabular}{lcc}
\hline Tingkat Pengetahuan & $\mathbf{f}$ & $\mathbf{\%}$ \\
\hline Baik & 644 & 71,00 \\
Cukup & 208 & 22,93 \\
Kurang & 55 & 6,06 \\
Jumlah & 907 & 100 \\
\hline
\end{tabular}

Sumber: Data Primer Tahun 2014

Berdasarkan Tabel 2 distribusi frekuensi responden (PUS) berdasarkan tingkat pengetahuan tentang KB di Argomulyo, Sedayu, Bantul, Yogyakarta tahun 2014 mayoritas memiliki tingkat pengetahuan baik tentang KB sebanyak 644 responden $(71,00 \%)$.

\section{Keikutsertaan KB pada Pasangan Usia Subur (PUS)}

Keikutsertaan KB pada pasangan usia subur (PUS) di 6 Dusun Desa Argomulyo terdiri 2 pilihan yaitu ikut serta dan tidak ikut serta. Tabulasi data keikutsertaan KB pada PUS disajikan dalam Tabel 3.

Tabel 3. Distribusi Frekuensi Keikutsertaan KB pada Pasangan Usia Subur (PUS) Berdasarkan Kriteria Ikut Serta dan Tidak Ikut Serta KB di Desa Argomulyo, Sedayu, Bantul, Yogyakarta Tahun 2014

\begin{tabular}{lcc}
\hline Keikutsertaan KB & f & \% \\
\hline Ikut Serta (Ya) & 610 & 67,3 \\
Tidak Ikut Serta (Tidak) & 297 & 32,7 \\
\hline Jumlah & $\mathbf{9 0 7}$ & $\mathbf{1 0 0}$ \\
\hline
\end{tabular}

Sumber: Data Primer Tahun 2014

Berdasarkan Tabel 3 dapat diketahui bahwa sebagian besar responden ikut serta dalam program KB sebanyak 610 responden $(67,3 \%)$, sedangkan PUS yang tidak ikut serta dalam program KB sebanyak 297 responden $(32,7 \%)$. 


\section{Analisis Bivariat}

Analisa bivariat dalam penelitian ini adalah hubungan antara tingkat pengetahuan tentang KB dengan keikutsertaan KB pada PUS di Argomulyo, Sedayu, Bantul,Yogyakarta tahun 2014. Tabulasi silang antara tingkat pengetahuan dengan keikutsertaan KB pada pasangan usia subur (PUS) disajikan dalam Tabel 4.

Berdasarkan data di atas diketahui bahwa responden yang memiliki pengetahuan baik namun ikut serta dalam program KB sebanyak 435 responden dengan persentase $67,5 \%$. Sedangkan responden yang memiliki tingkat pengetahuan baik namun ikut serta dalam program KB sebanyak 209 responden dengan persentase $32,5 \%$. Mayoritas keikutsertaan KB pada tingkat pengetahuan responden berpengetahuan baik dan cukup, dengan persentase tertinggi keikutsertaan KB pada tingkat pengetahuan cukup yaitu $68,8 \%$ (143 responden) sedangkan yang tidak ikut serta persentase tertinggi pada kelompok responden yang memiliki pengetahuan kurang dengan persentase $41,8 \%$ (23 responden).

Uji analisa secara statistik hubungan antara tingkat pengetahuan tentang KB dengan keikutsertaan KB pada PUS menggunakan chi-square diperoleh $\chi^{2}$ $=2,292$ dengan $p$-value 0,318 atau lebih besar dari $\alpha(0,05)$ dan contengency coefficient atau kekuatan hubungan antara 2 variabel yaitu 0,05 menunjukkan kekuatan hubungan antara kedua variabel tersebut sangat rendah. Berdasarkan perhitungan tersebut hasil $p$-value lebih kecil sehingga Ha ditolak yang berarti tidak ada hubungan yang bermakna antara tingkat pengetahuan tentang KB dengan keikutsertaan KB pada PUS di desa Argomulyo, Sedayu, Bantul, Yogyakarta tahun 2014.

Menurut Notoatmodjo pengetahuan merupakan hasil tahu, dan ini terjadi setelah seseorang melakukan penginderaan terhadap suatu obyek tertentu. Penginderaan terjadi melalui panca indera manusia, yakni indera penglihatan, pendengaran, penciuman, rasa, dan raba. Sebagian besar pengetahuan manusia diperoleh melalui mata dan telinga(6).
Pengetahuan atau kognitif merupakan faktor yang sangat penting untuk terbentuknya tindakan seseorang. Pengetahuan dipengaruhi oleh pendidikan formal dimana pengetahuan sangat erat hubungannya dengan pendidikan yang tinggi, pendidikan tinggi diharapkan mempengaruhi luasnya pengetahuan seseorang. Akan tetapi perlu ditekankan bukan berarti seseorang yang berpendidikan rendah mutlak berpengetahuan rendah pula hal ini mengingat bahwa peningkatan pengetahuan tidak mutlak melalui pendidikan formal saja, akan tetapi juga melalui pendidikan non formal.

Menurut Hartanto pengetahuan calon akseptor (PUS) tentang KB salah satunya dipengaruhi oleh informasi yang diperolehnya(7). Setiap tenaga kesehatan berkewajiban memberikan informasi, motivasi yang jelas dan benar tentang KB kepada pasangan usia subur (PUS) sehingga mempunyai pengetahuan yang baik dan mempunyai kesadaran untuk mengikuti program KB. Dilihat dari tabel tabulasi silang perbedaan antara responden yang berpengetahuan baik dan cukup sebanyak 1,3\% sehingga responden yang berpengetahuan cukup masih sangat mudah untuk meningkatkan pengetahuan mereka menjadi berpengetahuan baik dengan tetap mendapatkan atau mengakses informasi tentang KB.

Perbedaan responden yang berpengetahuan cukup dengan kurang sebanyak $10,6 \%$ untuk keikutsertaan KB sehingga pihak terkait yaitu petugas kesehatan setempat perlu memberikan apersepsi tentang KB kepada responden dengan pengetahuan cukup sehingga responden berpengetahuan cukup mendapat pengetahuan tentang KB yang lebih spesifik yang diharapkan ketidaktahuan responden tentang KB dapat memotivasi untuk ikut serta dalam program KB setelah responden mengetahui tentang KB secara spesifik. Motivasi dan niat responden untuk meningkatkan pengetahuan berasal dari diri responden sendiri didukung petugas kesehatan yang terus menerus memberikan informasi tentang KB seperti informasi mendasar meliputi pertanyaan tentang manfaat $\mathrm{KB}$, kesalah pengertian tentang metode KB tertentu, terlebih cara kerja ataupun

Tabel 4. Tabulasi Silang antara Tingkat Pengetahuan tentang KB dengan Keikutsertaan KB pada PUS di Argomulyo, Sedayu, Bantul, Yogyakarta Tahun 2014

\begin{tabular}{|c|c|c|c|c|c|c|c|c|c|}
\hline \multirow{3}{*}{$\begin{array}{c}\text { Tingkat } \\
\text { Pengetahuan KB }\end{array}$} & \multicolumn{4}{|c|}{ Keikutsertaan KB } & \multirow{2}{*}{\multicolumn{2}{|c|}{ Total }} & \multirow{3}{*}{$\chi^{2}$} & \multirow{3}{*}{ p-value } & \multirow{3}{*}{$\begin{array}{l}\text { cont } \\
\text { coeff }\end{array}$} \\
\hline & \multicolumn{2}{|c|}{ Ikut } & \multicolumn{2}{|c|}{ Tidak Ikut } & & & & & \\
\hline & $f$ & $\%$ & $f$ & $\%$ & f & $\%$ & & & \\
\hline Baik & 435 & 67,5 & 209 & 32,5 & 644 & 100 & 2,292 & 0,318 & 0,05 \\
\hline Cukup & 143 & 68,8 & 65 & 31,3 & 208 & 100 & & & \\
\hline Kurang & 32 & 58,2 & 23 & 41,8 & 55 & 100 & & & \\
\hline Total & 610 & 67,3 & 297 & 32,7 & 907 & 100 & & & \\
\hline
\end{tabular}

Sumber: Data Primer Tahun 2014 
penggunaan alat KB yang belum diketahui oleh responden setempat.

Menurut Notoatmodjo bahwa perilaku yang didasari oleh pengetahuan akan lebih langgeng daripada perilaku yang tidak didasari oleh pengetahuan(8). Penggunaan KB yang didasarkan atas pengetahuan tentang alat kontrasepsi atau KB dapat menimbulkan ketenangan karena pasangan usia subur menyadari efek samping penggunaan kontrasepsi (KB) sehingga lebih siap dalam menghadapinya. Sebaliknya jika penggunaan KB tidak didasari pengetahuan maka hal ini menimbulkan kekhawatiran tentang alat KB yang digunakan sehingga mempengaruhi pasangan usia subur untuk mengikuti atau tidak mengikuti program KB.

Pengetahuan tentang kontrasepsi atau KB adalah salah satu faktor yang mempengaruhi keikutsertaan dalam KB, namun selain tingkat pengetahuan, keikutsertaan KB juga dipengaruhi oleh faktor lain. Secara teoritis partisipasi atau keikutsertaan berarti turut berperan serta dalam suatu kegiatan, keikutsertaan atau peran serta dalam suatu kegiatan, peran serta aktif atau proaktif dalam suatu kegiatan(8).

Keikutsertaan dapat didefinisikan secara luas dalam bentuk keterlibatan dan keikutsertaan masyarakat secara aktif dan sukarela, baik karena alasan-alasan dalam dirinya (intrinsik) maupun dari luar dirinya (ekstrinsik) dalam keseluruhan proses yang bersangkutan. Seseorang yang memiliki pengetahuan baik tentang sesuatu akan memiliki partisipasi positif tentang sesuatu akan membuat individu tersebut memiliki sikap dan perilaku yang positif terhadap hal tersebut dalam hal ini keikutsertaan KB(9).

Namun teori tersebut tidak beriringan dengan hasil penelitian bahwa tingkat pengetahuan yang baik tidak berhubungan dengan keikutsertaan KB. Dilihat dari sudut pandang WHO bahwa yang menyebabkan seseorang berperilaku tertentu adalah karena adanya faktor pokok dan alasannya yakni: pemikiran dan perasaan yakni dalam bentuk pengetahuan, persepsi, sikap, kepercayaan-kepercayaan dan penilaian seseorang terhadap objek(8).

Pengetahuan diperoleh dari pengalaman sendiri atau pengalaman orang lain sehingga untuk keikutsertaan KB setiap orang mempunyai pengalaman yang berbeda-beda sehingga tingkat pengetahuan yang mereka peroleh juga berbeda sehingga hal ini akan menimbulkan 2 kondisi dimana mereka mempunyai pengetahuan baik tentang KB namun mereka mempunyai pengalaman yang tidak baik ketika ikut serta dalam program KB, hal ini mendorong mereka yang berpengetahuan baik cenderung tidak mengikuti KB karena pengalaman yang buruk tentang $\mathrm{KB}$, begitupun sebaliknya jika pengetahuan cukup maupun kurang tentang KB namun pengalaman mengikuti KB baik atau bermanfaat maka kecenderungan mereka mengikuti KB.

Kepercayaan sering diperoleh dari orang tua, kakek, nenek, dimana seseorang itu menerima kepercayaan berdasarkan keyakinan dan tanpa adanya pembuktian terlebih dahulu hal ini terkait mitos tentang KB yang negatif. Sikap menggambarkan suka atau tidak suka seseorang terhadap objek tertentu dalam hal ini alat kontrasepsi atau metode KB. Sikap sering diperoleh dari pengalaman sendiri atau orang lain yang paling dekat yaitu ibu, kakak perempuan, nenek, keluarga. Meskipun orang tersebut memiliki pengetahuan yang baik namun sikap suka atau tidak suka terhadap pemakaian KB adalah berdasarkan pengalamannya sendiri atau dari orang lain yang ada didekatnya. Sehingga pengalaman dan keluarga adalah sumber pengetahuan non formal yang didapat seseorang yang dapat mempengaruhi perilakunya.

Hasil analisis bivariat penelitian ini menyatakan bahwa tidak terdapat hubungaan yang signifikan antara tingkat pengetahuan tentang $\mathrm{KB}$ dengan keikutsertaan KB pada PUS di desa Argomulyo, Sedayu, Bantul, Yogyakarta tahun 2014. Penelitian ini tidak sejalan dengan penelitian oleh Ekasari yang menunjukkan bahwa tingkat partisipasi pasangan usia subur dalam program KB di Kelurahan Timbangan, Kecamatan Indralaya Utara, Ogan Ilir ditentukan oleh tingkat pengetahuan mengenai alat kontrasepsi sebesar $10,48 \%$ dan sisanya yaitu $89,52 \%$ dipengaruhi oleh faktor lain yang tidak diteliti(10). Penelitian Rahma tentang faktor-faktor yang berhubungan dengan pemilihan kontrasepsi non IUD pada akseptor KB wanita usia 20-39 tahun menunjukkan tidak ada hubungan tingkat pengetahuan dengan pemilihan kontrasepsi non IUD pada akseptor KB wanita usia 20-39 tahun(11).

Dalam teoriWHO, dijelaskan bahwa pengetahuan dipengaruhi oleh pengalaman seseorang, faktorfaktor luar orang tersebut (lingkungan), baik fisik maupun non fisik dan sosial budaya yang kemudian pengalaman tersebut diketahui, dipersepsikan, diyakini sehingga menimbulkan motivasi, niat untuk bertindak dan pada akhirnya terjadi perwujudan niat berupa perilaku. Berdasarkan teori tersebut banyak faktor yang mempengaruhi pengetahuan seseorang sehingga hasil penelitian ini menghasilkan hubungan yang tidak signifikan. Sementara itu dari penelitian payung yang telah kami lakukan menunjukkan ada faktor yang terkait dengan keikutsertaan KB yaitu faktor dukungan keluarga dan tingkat ekonomi (pengeluaran). Dukungan keluarga yang tinggi 
menyebabkan PUS ikut serta dalam program KB. Dukungan keluarga mengacu pada suatu dukungan yang dipandang oleh anggota keluarga lain sebagai hal yang bermanfaat dimana dukungan keluarga yang tinggi dan ikut KB sebanyak 416 responden $(93,3 \%)(12)$.

Hal ini menunjukkan meskipun tingkat pengetahuan tidak berhubungan dengan keikutsertaan KB pada PUS namun faktor lain seperti dukungan keluarga adalah faktor yang berhubungan dengan keikutsertaan KB. Artinya meskipun tingkat pengetahuan responden di tempat penelitian rendah, namun jika keluarga mendukung maka akan mengikuti KB. Faktor lain yang berhubungan dengan keikutsertaan KB yaitu tingkat ekonomi atau pengeluaran sehingga dapat kita simpulkan bahwa Tingkat pengetahuan tidak sangat menentukan dalam keikutsertaan KB pada PUS di desa Argomulyo, Sedayu, Bantul, Yogyakarta tahun 2014.

Berdasarkan keseluruhan penelitian yang telah dilakukan pengetahuan tetap mempunyai peranan penting dalam mendorong keikutsertaan KB, dimana dengan pengetahuan yang baik diharapkan PUS terdorong atau termotivasi untuk mengikuti program KB. Hasil penelitian yang menunjukkan tidak ada hubungan pengetahuan KB dengan keikutsertaan PUS dalam program KB dipengaruhi oleh beberapa faktor sehingga pengetahuan PUS perlu tetap terus ditingkatkan karena dengan pengetahuan maka PUS dapat mendasari tindakannya untuk mengikuti KB dengan pengetahuan yang PUS miliki sehingga ketika PUS mengikuti program KB, keikutsertaan tersebut dapat lebih langgeng.

\section{SIMPULAN DAN SARAN}

Berdasarkan hasil penelitian dapat disimpulkan pengetahuan responden (PUS) tentang KB di Desa Argomulyo, Sedayu, Bantul, Yogyakarta mayoritas berpengetahuan baik sebanyak 644 responden (71,00\%). Keikutsertaan responden dalam program KB sebanyak 610 responden $(67,3 \%)$, sedangkan 297 responden $(32,7 \%)$ tidak ikut serta dalam program KB. Persentase tertinggi keikutsertaan KB berdasarkan tabulasi silang pada responden yang berpengetahuan cukup yaitu 143 responden $(68,8 \%)$, sedangkan persentase tertinggi tidak ikut serta dalam program KB pada pengetahuan cukup sebanyak 23 responden (41,8\%). Tidak ada hubungan signifikan antara Tingkat Pengetahuan tentang KB dengan Keikutsertaan KB pada PUS di Desa Argomulyo, Kecamatan Sedayu, Kabupaten Bantul, Yogyakarta tahun 2014 yang ditunjukkan dengan uji statistik chi- square hasil $p$-value 0,318 . Tingkat hubungan antara kedua variabel tingkat pengetahuan tentang $K B$ dengan variabel keikutsertaan KB pada PUS sangat rendah, ditunjukkan dengan koefisien kontingensi 0,05 . Saran bagi PUS agar lebih meningkatkan pengetahuan tentang KB.

\section{RUJUKAN}

1. BPS. Profil Dusun Sedayu 2013. Badan Pusat Statistika Propinsi DIY. Yogyakarta; 2013.

2. Mustakim. Cakrawala KB, Kependudukan dan Pemberdayaan Keluarga. Jakarta: Referensi; 2012.

3. Handayani S. Buku Ajar Pelayanan Keluarga Berencana. Yogyakarta: Pustaka Rihama; 2010.

4. BKKPPKB. Data Hasil Kegiatan Program KB Nasional Kabupaten Bantul. Yogyakarta: BKKPPKB; 2013.

5. Anisyah D. Faktor-faktor yang Mempengaruhi Keengganan Akseptor KB Dalam Memilih IUD Di Dusun Beran Kelurahan Canden Kecamatan Jetis Kabupaten Bantul Yogyakarta. STIKES Alma Ata Yogyakarta; 2013.

6. Machfoedz I. Metodologi Penelitian Kuantitatif \& Kualitatif Bidang Kesehatan Keperawatan Kebidanan Kedokteran. Yogyakarta: Fitramaya; 2013.

7. Hartanto H. Keluarga Berencana dan Kontrasepsi. Jakarta. Pustaka Sinar Harapan; 2004.

8. Notoatmodjo. Promosi Kesehatan dan IImu Perilaku. Jakarta: Rineka Cipta; 2007.

9. BKKBN. Badan Kebijakan Program Keluarga Berencana Nasional. Jakarta; 2004.

10. Ekasari N. Hubungan Tingkat Pengetahuan Mengenai Alat Kontrasepsi Dengan Tingkat Partisipasi Dalam Program KB Studi pada Pasangan Usia Subur (PUS) yang Menggunakan Alat Kontrasepsi Jangka Pendek di Kelurahan Timbangan, Kecamatan Indralaya Utara, Ogan Ilir. Universitas Sriwijaya; 2012.

11. Rahma A. Faktor-Faktor Yang Berhubungan Dengan Pemilihan Kontrasepsi Non IUD Pada Akseptor KB Wanita Usia 20-39 Tahun. Universitas Diponegoro; 2011.

12. Wahyuni, Handayani D. Hubungan Dukungan Keluarga Dengan Kepatuhan Lansia Dalam Mengikuti Posyandu Lansia Di Posyandu Lansia Jetis Desa Krajan Kecamatan Weru Kabupaten Sukoharjo. Jurnal STIKES. 2012;9:49-50. 